\title{
Membrane-based downhole oil-water separation (DOWS) technology: an alternative to hydrocyclone-based DOWS
}

\author{
Mohit Patel $^{1} \cdot$ Jigarkumar Patel ${ }^{1} \cdot$ Yogendrasingh Pawar $^{1} \cdot$ Nehal Patel $^{1} \cdot$ Manan Shah $^{2}$
}

Received: 9 December 2018 / Accepted: 5 February 2020 / Published online: 24 February 2020

(c) The Author(s) 2020

\begin{abstract}
Produced water handling has become one of the central concerns for the oil and gas industry today. Produce water (water cut) increases as the field grows old, which brings the additional handling cost to the project. The additional expense could be in terms of lifting cost, treatment, maintenance, tubular scaling, corrosion problems, bacteria, naturally occurring radioactive material and environmental regulations, etc. To address this problem, the hydrocarbon industry developed the downhole oilwater separation (DOWS) technology in the 1990s. In spite of having such cost-effective and environment-friendly solutions, the industry has limited sites using this technique. Thus, there is uttermost need to evaluate the problems in practicality of the current hydrocyclone-based and gravity-based DOWS and find a reliable solution to it. The membrane-based separation methodology represents the coherent solution to robust the downhole separation system that does not require any moveable equipment with advance sensors and mechanical tools. If the reservoir is well characterized and a reliable simulation model is built, it is possible to predict the optimal time for the placement of a specific length of membrane in the well depending on the layer concerned and inclination of the well. Apart from designing the thin and porous hydrophobic and oleophilic membranes, there are plenty of field challenges which have put constraints on the practicality of membrane-based DOWS. The major constraints are durable range of separation pressure, fouling, separation process design, membrane-shear durability. The objective of this study is to present a novel model of PTFE (polytetrafluoroethylene) membrane-based downhole oilwater separation system with its over all functionality and addresses the constraints mentioned above with promising existing working solutions. Moreover, the study also literature reviews and compares the expenditure and maintenance involved in manufacturing, installation, operating and maintenance of system, between the conventional hydrocyclone-based downhole water separation and the proposed (PTFE) membrane-based DOWS.
\end{abstract}

Keywords Downhole oil-water separation $\cdot$ Oleophilic $\cdot$ Polytetrafluoroethylene $\cdot$ Tangential ultrafiltration $\cdot$ Crossflow separation · Durable

\section{Introduction}

The term produced water in oil and gas industry means the water that is lifted or flowed by its own to the surface from the oil and gas reservoir while producing hydrocarbons. It can be in the form of reservoir fluid, any treatment chemical carrier or any injected fluid. This produced water can be termed as an unwanted by-product, which keeps

Manan Shah

manan.shah@spt.pdpu.ac.in

1 School of Petroleum Technology, Pandit Deendayal Petroleum University, Gandhinagar, India

2 Department of Chemical Engineering, School of Technology, Pandit Deendayal Petroleum University, Gandhinagar, India on increasing with the maturity of the field. Water cut is defined as the ratio of total water produced in a main stream to the total fluid produced. This water cut reach a significant amount in a water drive reservoir. The water cut increases as the field grows old with, which brings the following maintenance and handling cost to the project apart from reducing oil production: (a) lifting cost, (b) treatment, (c) maintenance, (d) tubular scaling, corrosion problems (Fakhrul-Razi et al. 2009). Worldwide, this maintenance and handling cost is around 40,000 million dollars. World produces about 75 million bbl./day (Crabtree and Romano 2000) along with the estimated water production of 300-400 million bbl./day. So, the ratio of 4-5 bbl. water per bbl. oil extracted is a cautious approximation. 
Current hydrocarbon extraction activities produce hydrocarbon along with water to surface and have special surface facilities to separate it to oil, gas and water. As industry predominantly uses the three-phase horizontal separator in the first stage of the separation of oil from the other constitutive, separators are designed in such a manner that the residence times of the oil and the water are maximized. Solids are also produced in the main stream; thus, separation and disposal of them should also be considered. The separation of all three fluids and solids is governed by Stokes law (FakhrulRazi et al. 2009). The separated fluid stream always contains some small droplets dispersed in the water along with some solid contents. Due to the strict environmental regulations, this separated stream should also be treated before dumping it in environment (Papakostas 2017). Apart from that, this stream also contains some significant amount of oil which can add value to the project.

These operation costs can be exponentially reduced by the employment of DOWS. Downhole water separation is existing technology which can segregate water and oil inside the wellbore which in turn eliminates the need for surface separation. All DOWS installations have been made as retrofits to existing wells with standard pumps (Veil 2001). As other downhole water separation processes require a moveable part or equipment with advance sensors with operating, designing and maintenance intricacy and need rigorous planning for the optimized separation of oil and gas from water, applying a membrane-based separation process will give a coherent solution to these operations. Fernández et al. (2001) and Tweheyo et al. (2003) have worked in the direction of membrane separation technology, and from study it can be judged that through the development in membrane science the membrane-based DOWS could be introduced to the petroleum industry. Based on reservoir characterization and simulation model analysis for future trend analysis specific time, depth and length for deployment of the membrane inside the tubing can be determined (Ogunsina and Wiggins 2005). The proposed mechanism will consist of a thin and porous hydrophobic and oleophilic membrane made from polytetrafluoroethylene (PTFE) (Qing et al. 2017), for separation of the inflow and two outflow ports in ultrafiltration modules. Here, nanopores of the membrane will act as capillary and fluid flow will depend on the fluid rheology (Mozaffari et al. 2016). Due to its oil-wet in nature, only oil will go under the capillary-driven flow after expelling the water (Mozaffari et al. 2016). As it is oleophilic in nature, it has receding contact angle phenomena during the fluid flow but not to the much extent of wettability alteration. There won't be any or negligible adsorption of any molecule during the process of separation process; otherwise, it will reduce the efficiency of separation (Darjani et al. 2017). Separated water from oil/gas will be reinjected in the same reservoir at below oil-water contact or in distinctive reservoir with high injectivity index by pump. DOWS technology predominantly depends on properties of injection and production zone. Injection zone should have sufficient porosity and permeability so that we can dispose brine into it using pump. If the disposal fluid contains sand size particles which can clog injection zone, permeability of injection zone will decrease. This will lead to loss in injectivity. As complex and delicate hydrocyclone-based DOWS equipment will be fitted in very small cross-sectional area and as they are exposed to very high flow rate, risk of corrosion/erosion increases (Ogunsina and Wiggins 2005; Gao et al. 2007). PTFE can be manufactured using electrospinning and sintering from the colloidal nanoparticle of PTFE-PVA emulsion via nucleation and growth of thin fibrous membrane (Mozaffari et al. 2017, 2018; Li et al. 2018). The proposed membrane-based DOWS is simple to construct and its working configuration gives us plenty of options to employ sand filters which could address sand issues. Further, it consists of gas injection valves or de-latching along with rotation and reverse circulation mechanism for fouling and clogging cleaning purposes. The proposed model can be also utilized in different artificial recovery mechanism; the installation does not require much surface control connections. As the working pressure of the membrane is as low as $20 \mathrm{kPa}$, there will be a very less pressure drops across the filters (Qing et al. 2017).

The major constraints associated with the practicality of membrane are durable range of separation pressure, fouling, separation process design, membrane-shear durability. Its overall functionality addresses the constraints mentioned above with promising existing working solutions. As the proposed membrane model of DOWS can separate the water at nanolevel, it can drastically reduce or nullify the cost of lifting water, treatment, maintenance, tubular scaling, corrosion problems, bacteria, naturally occurring radioactive material and environmental regulations, etc. It has been concluded that the proposed PTFE membrane can separate oil and water at the pressure differential of $2000 \mathrm{psi}$ and has the tensile strength of 2857 psi. The membrane can allow the flow of $1215 \mathrm{~L} \mathrm{~m}^{-2} \mathrm{~h}^{-1}$ at gravity separation. Further, the framework fibers of this membrane can bear extremely rough conditions (Qing et al. 2017). These amalgamations of property demonstrate the practicality of this model. Conversion of a well from a regular pump to conventional hydrocyclone-based DOWS technology is a relatively expensive undertaking, including both the cost of the DOWS and well workover expenses. A decision tree has been worked out by the Blanco and Davies (2001) which helps in decision making about employment of DOWS technology. The economics factor of installation and oil recovery economics has been explained by Jokhio et al. (2002). Installation of an electric submersible pump DOWS system costs about two to three times more than the replacement of a conventional electrical submersible pump. The expense often ranges from 90,000 to 
250,000 USD, excluding the workover costs. Workover costs can often exceed 100,000 USD. Gravity separator DOWS cost less, ranging from 15,000 to 25,000 USD. One example of a complete installation of this type costs 140,000 USD in which hydrocyclone unit has cost of 2000-10,000 USD (Gao et al. 2007). In contrast to it, the proposed robust polytetrafluoroethylene (PTFE) membrane just involves a simple electrospinning-sintering strategy and the proposed model has very convenient and less time-consuming workover jobs. This depicts that the proposed membrane-based downhole water separation technology is more economically beneficial and has potential to lionize in hydrocarbon industry. As PTFE membrane can maintain its super-hydrophobicity under both acidic and alkaline conditions, there is no issue of contamination of various corrosive components such as salts, acids and alkaline. And as PTFE membrane can maintain high water static contact angle at high temperature as $150{ }^{\circ} \mathrm{C}$, additionally the system seems to have no problem with workover operations like Hot Oil Circulation, N2 job and Acid job (Qing et al. 2017). As PTFE membrane is oleophilic type, it will increase the chance of asphaltene precipitation in the presence of crude oil with pentane and heptane (Mozaffari et al. 2015) or the pressure near the bubble point pressure. So, the toluene can be added into the system as the asphaltene is more soluble in it, and it will remain into the solution (Mozaffari et al. 2015). Therefore, in heavy oil reservoir, it can be utilized with some special injecting unit.

The novelty of the new proposed model is in the ability to effectively separate the water and oil into two streams at bottom hole or at any depth in wellbore without any moving stack and unnecessary electrical supply and thus reduces the water handling cost.

\section{Problems encountered in conventional DOWS and its possible solution by membrane-based DOWS}

The major issues with the DOWS application are due to the hardware or the formation conditions (Ogunsina and Wiggins 2005; Gao et al. 2007).

(a) Mechanical/corrosion Issues The most challenging part in DOWS is to fit the separator into the bottom hole and providing the connecting tubing from separator to ESPs by passing. As this tubing is very thin, this is subjected to very high speed flow. This causes the erosion and corrosion in the bypass tubing. Further, as they are installed somewhat far from center assembly, there remains the change in failure/ breakage of this tubing.

(1) In membrane system, there is no need for bypass system as only one ESI is required in the separator and injection process.
(2) Membrane module shell size can be modified according to the wellbore dimensions by adjusting diameter-tolength relationship of module shell. For example, if we require membrane module for 5" casing and 7" casing, we can employ module shell with a smaller diameter of 5" casing by increasing its length to increase the separation area of the membrane, and similarly for 7" casing the larger diameter module shell with a greater number of individual separation membrane pipes could be applied by reducing the depth of module. This can improve the techno- economics of the project.

(b) Solids plugging The solids like matrix, sands, formation solids at bottom hole can lead to the mechanical disturbance like chocking and breakdown of bottom hole equipment like gravity separator, hydrocyclones, ESPs, progressive cavity pumps or bypass tubing. As the membrane shell and tube separator allows the freedom to select injection zones at depth throughout the wellbore, the problem of solid plugging can be addressed in very effective manner. The company can thus select any depth in the tubing to place the membrane separation system while simultaneously applying gravel pack or frack pack.

(c) Isolation problems To avoid the connection of injection zone ideally, it is needed that there is good cementation at bottom hole or both the zones are adequately far from each other. The former can be related to completion strategy. In hydro-cyclone based DOWS, the injection zone is usually at deeper depths than production interval. Moreover, to avoid drilling cost, they are selected near the production zone. With Membrane based DOWS, the zone could be selected at any depth so it offers freedom to select injection zone which is a good practice for zonal isolation.

The far away zone can be made as injection zone.

(d) Injectivity decline For the DOWS technology to operate or work properly, the disposal zone should have sufficient petrophysical parameters to accept brine within the pressure capability (limitation) of the pump. Permeability is damaged by improper fluid contacts with sensitive sands; the disposal zone was clogged by particles in the produced water. Most of the time, injectivity decreases because water flooding operations have various contaminants. This phenomenon is called as formation damage which can lead to a significant loss in productivity as injectivity. It is challenging to install the separator inside the wellbore, especially when channels to bypass oil stream around the pump and motor equipment should be installed into a small cross section and exposed to very rates. Above situations generate risks of erosion and corrosion. As the bypass tubing has thin wall configuration and is assembled outside the main string, this has great potential of failure while installation. In horizontal or inclined well, the severity increases. Membranebased DOWS can't solve the problem of injectivity, but as

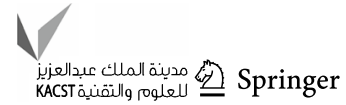


mentioned above the injection zone can be changed to new injection zone. Thus, the operator can have multiple injection zones as per the required parameter.

\section{Selection of potential candidate}

It has been observed that $60 \%$ of the worldwide installation of DOWS has improved techno-economics of the project (Gao et al. 2007). There have been very few studies in deciding the criteria for installation of DOWS. One such engineering feasibility study was carried out by Alhoni et al. (2003) to select potential candidate well. Peats and Schrenkel (1997) and Matthews et al. (1992) have also studied the particular fields to describe the selection criteria for that particular field. According to Gao et al. (2007), the primary criteria for selecting a better candidate bore hole to implement the present DOWS technology are as follows:

(a) The suitable water disposal strata

(1) The disposal zone must have suitable porosity and permeability to store disposal stream volume throughout life of well.

(2) The disposal zone should not react with water. This can bring down hole complications as well as damage the skin of disposal reservoir.

\section{(b) A suitable production zone requirement}

(1) Solid management.

(1) (2)The specific gravity should be 150 API or higher. The net produce fluid for gravity-based DOWS should be lesser than 1250 bbl./day. For hydrocyclone-based DOWS, water cutoff should be more than $90 \%$ and producing at higher rates.

\section{(c) Well bore geometry necessities}

The application with the present technology DOWS can be difficult in deviated and horizontal wells. The present technology can't be applied to casing size smaller than 5.5". There should be adequate separation between producing and injection zone to avoid channeling and effectively accommodate the separation module between zones.

\section{Operations of membrane-based DOWS}

The membrane-based DOWS can reduce or nullify these cost, mechanical failure, continuous monitoring and system efficiency issues (Tweheyo et al. 2003). The proposed membrane module design is inspired by module design of Yang et al. 2013), Marriott (2001), Frick and Filtration Group (2017). The proposed system employs tangential ultrafiltration technology to separate oil and water (retentate) stream. This type of separation is called cross-flow separations (A Publication of Samco Technologies). They are well known to minimize fouling by concentration polarization effects (Vizzi 2016). Ultrafiltration is a versatile system which solves variety of separation process problems by reducing operations cost, allowing flexibility and leaving lesser footprints. Membrane separation is a filtration process which employs semipermeable membrane to separate two liquid streams. The unwanted liquid stream may contain the fouling particles suspended in liquid. Ultrafiltration separates at the level of $100 \mathrm{~nm}$ to $1 \mathrm{~nm}$ pore diameters (A Publication of Samco Technologies). So ultrafiltration works on the principle of size-neglecting. Incorporation size-neglecting and hydrophobicity of membrane can help us in segregation of oil stream and water stream at bottom hole itself. The oil stream can be termed as filtrate, and the water stream can be termed as retentate.

The producing stream enters the separation module in the shell through the inlet probes shown in Fig. 1. This inlet stream flows parallel to surface of individual membrane pipes. The parallel filtration and oleophilicity-hydrophobicity separates the inlet fluid in producing oil stream and a separate retentate stream, which flows along the membrane module to top of the shell. The top of the shell has outlet probes which allow retentate stream to pass. This retentate stream is a disposing fluid which is pumped to a permeable formation with the help of pump and motor governing it. The disposal zone is isolated from the producing formation by means of packer. The process is depicted in Fig. 1 .

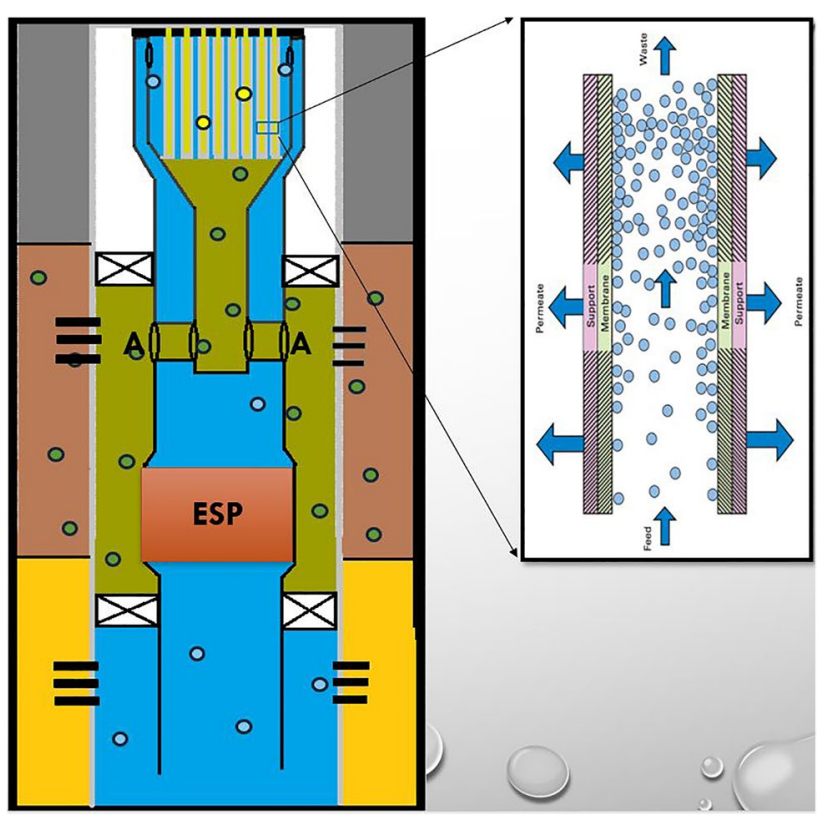

Fig. 1 Schematic illustration of PTFE membrane-based DOWS 


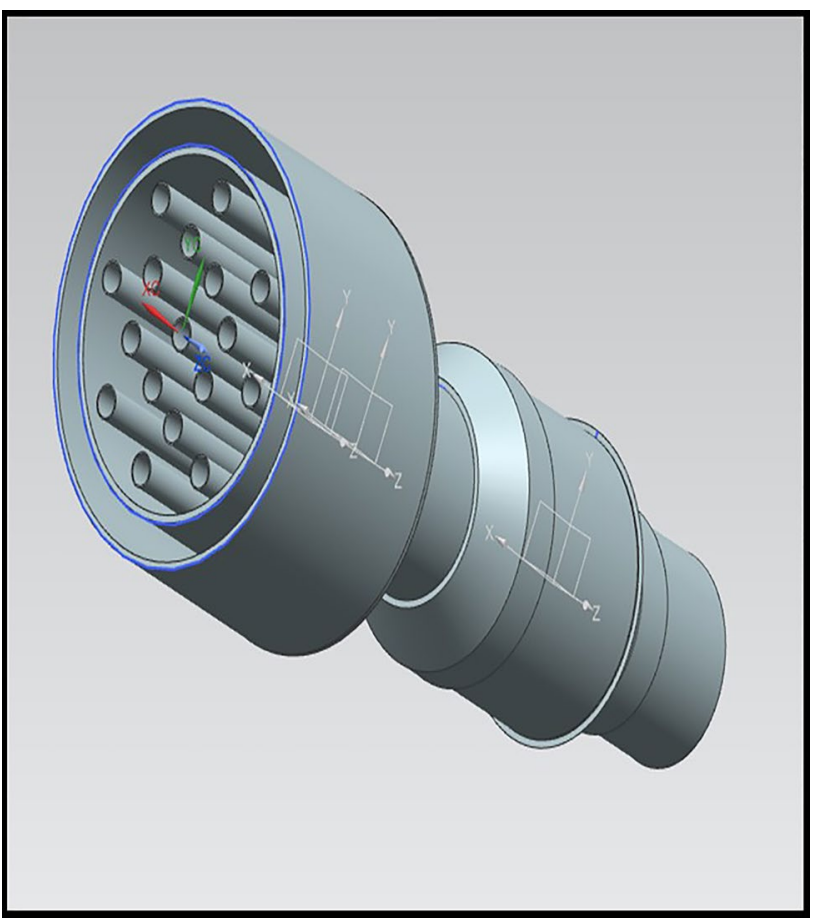

Fig. 2 PTFE membrane model (Auto CAD)

Moreover, the design shown in Fig. 1 helps operator to choose any interested disposal zone in the well bore. The inherent benefit of this process includes high separation flux per unit area, light and flexible, adjustable pore volumes and high surface-to-volume ratio. Also, the cross-flow filtration separates constantly which helps in preventing fouling or choking issues which can block the membrane. The separation area of the module can be adjusted by increasing the length of the modules or by connecting two or more modules in series. The AutoCAD image of the proposed model is shown in Fig. 2.

\section{Materials and manufacturing process of PTFE membrane}

\section{Materials}

PVA powder (average MW 90,000-98,000, 97-99\% hydrolyzed), PTFE emulsion (65 wt\% dispersion in $\mathrm{H} 2 \mathrm{O}$, PTFE particle size around $250 \mathrm{~nm}$ ), oil (chloroform, $1.5 \mathrm{~g} / \mathrm{cm} 3$, $0.560 \mathrm{CP}$ ), and sodium hydroxide and hydrochloric acid were used. Oil red $\mathrm{O}$ and methylene blue and all the chemicals were of analytical grade and were used without further clearing. Deionized water was used in this process (Qing et al. 2017). (a)

(b)

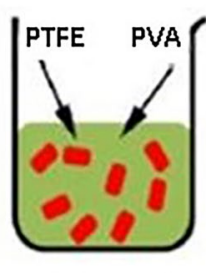

Doping Solution

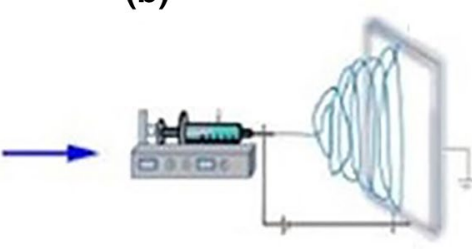

Electrospinning (c)

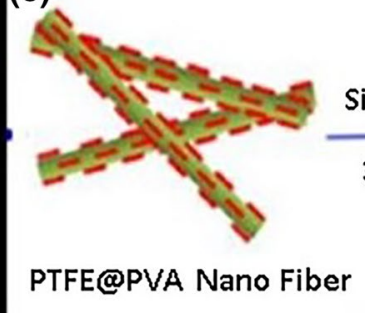

(d)

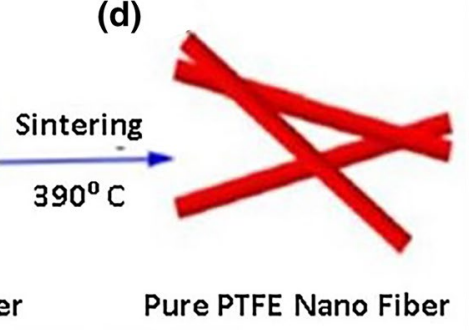

Fig. 3 Schematic illustration of the procedure for manufacturing of PTFE nanofibrous membrane

\section{Manufacturing process of PTFE membrane}

Initially, a PVA aqueous solution was prepared by dissolving $12 \mathrm{~g}$ PVA powder in $100 \mathrm{~g}$ water for 6 and half ours at $85{ }^{\circ} \mathrm{C}$. After that, a doping solution for electrospinning was prepared by mixing $12 \mathrm{~g}$ PVA aqueous solution and $25 \mathrm{~g}$ PTFE emulsion for $12 \mathrm{~h}$ at room temperature around $20{ }^{\circ} \mathrm{C}$. A PTFE membrane was manufactured by electrospinning process. During the spinning process, the fluid flow rate was kept at $0.5 \mathrm{~mL} \mathrm{~h}^{-1}$, the voltage applied to the needle was $15 \mathrm{kV}$, and the spinneret/collector distance was kept at $15 \mathrm{~cm}$. Lastly, a sintering process was carried out for the PTFE membrane in a muffle furnace (in air medium) at $390^{\circ} \mathrm{C}$ (Zhou et al. 2014). This temperature was higher than the melting point of PTFE $\left(\sim 330^{\circ} \mathrm{C}\right)$ (Xiong et al. 2009) and the decomposition temperature of PVA (above $270{ }^{\circ} \mathrm{C}$ ), the PVA nanofiber was supposed to decompose, and PTFE particles dispersed on the PVA nanofiber were supposed to fuse together to compose a perpetual nanofiber (Qing et al. 2017).

\section{Manufacturing economics of polytetrafluoroethylene (PTFE)}

A robust polytetrafluoroethylene (PTFE) nanofibrous membrane can be made easily by a simple electrospinning-sintering strategy. A series of techniques have been prosperously 
developed to fabricate porous super-hydrophobic and superoleophilic membranes (Yong et al. 2016), including phase disunion, chemical vapor deposition, solgel method, electrospinning, electrochemical deposition, chemical etching (Celia et al. 2013). Among them, electrospinning is gaining incrementing attention as a low-cost, simple, scalable nanomanufacturing technique (Nuraje et al. 2013) (Fig. 3).

Materials for manufacturing PTFE membrane

PVA (poly vinyl alcohol) powder-3.7\$/kg.

PYFE powder-14.3\$ $/ \mathrm{kg}$.

Hydrochloric acid- $0.3 \$ / \mathrm{kg}$.

Sodium hydroxide powder- $-1.43 \$ / \mathrm{kg}$.

Price of electrospinning-sintering process PTFE membrane market cost is around $1000 \$$.

Gravity separator DOWS cost less, ranging from 15,000 to 25,000 USD. Hydrocyclone unit has cost of 500010,000 USD. So, PTFE membrane-based DOWS system is better at economical option compared to other DOWS systems.

\section{Factors affecting performance of DOWS system}

\section{(1) Oil separation efficiency (eff)}

It is the practical definition of separation of the purity of individual discharge streams. Many references quantify the relative phase composition of the separated streams in the form of a percentage by volume measurement. It is expressed as:

Eff $=\frac{\left(Q_{\text {oil-overflow }}\right)}{\left(Q_{\text {oil-inlet }}\right)} * 100$

where $Q_{\text {oil-overflow }}=$ the flow rate of oil at the overflow and $Q_{\text {oil-inlet }}=$ the flow rate of the oil at inlet (Fig. 4). Normally for hydrocyclone-based DOWS, it is around $75-85 \%$ when PTFE membrane gives nearly $99 \%$ separation of oil and water (Qing et al. 2017). PTFE membrane is intrinsically hydrophobic (Raza et al. 2014). Water contact angle on a smooth PTFE membrane surface is between 1000 and 1150 (Burkarter et al. 2007). Disseverment of fluids in a hydrocyclone is not $100 \%$ consummate. Some oil is carried along with the water fraction, and a paramount portion of water (typically 10-15\%) is brought to the surface with oil engenderment (Awab and Mohammed 2015). Some of oil content (typically between 10 and $200 \mathrm{ppm}$ of oil) in injecting water can damage the formation.

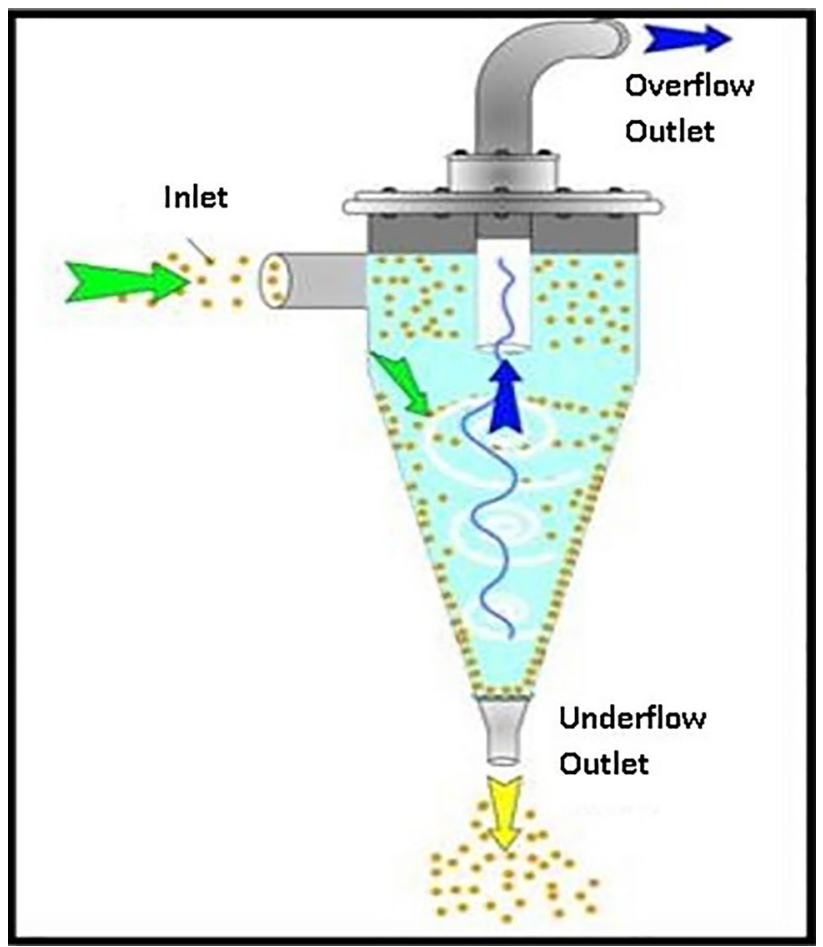

Fig. 4 Schematic figure of hydrocyclone

\section{(2) The pressure drop}

Under normal operation, there are two quantified pressure drops across a hydrocyclone. One is the distinction between inlet and rejected pressures, and the other is the distinction between inlet and outlet pressures. The first one is always greater than the second. The relationship between two different pressure drops is called "pressure difference ratio" (PDR) and is defined as:

$\operatorname{PDR}=\frac{\left(P_{\text {in }}-P_{\text {rej }}\right)}{\left(P_{\text {in }}-P_{\text {out }}\right)}$

where $P_{\text {in }}$ inlet pressure, $P_{\text {rej }}$ the rejected pressure or overflow outlet (oil), $P_{\text {out }}$ the pressure of under flow outlet (water).

PTFE membrane-based DOWS has a pressure drop around 3-5 psi because during process less energy loss occurs which is explained in Sect. 4 when hydrocyclonebased DOWS has pressure drop around 20-90 psi depending upon their size. Smaller units are usually operated at a higher pressure drop than the large ones. This more pressure drop in hydrocyclone is because of more energy required to spin the incoming fluid (Abdullah and Ahmed 2015). 


\section{(3) Chemical and mechanical stability}

PTFE membrane maintained its super-hydrophobicity (Liao et al. 2013), surface morphology and chemical composition under both acidic and alkaline or in extreme temperature conditions. PTFE membrane has corrosion resistivity in both acidic and alkaline environment (PH ranging from 1 to 13 ) (Qing et al. 2017). PTFE membrane hardly dissolves in any solvent. Tensile strength of PTFE membrane is $19.7 \mathrm{MPa}$ (2850 psi) (Liao et al. 2013). Its corrosion resistance and mechanical stability show it could stand harsh environment existing in wellbore.

\section{(4) Permeate flux}

PTFE membrane generally has an immensely colossal area-to-volume ratio, high porosity, fine flexibility and controllable pore size leading to high permeate flux during oil/water disunion. The membrane can allow the flow of $1215 \mathrm{~L} \mathrm{~m}^{2} \mathrm{~h}^{-1}$ at gravity separation (Qing et al. 2017). Efficiency based on pore size is dependent on fluid type and compositions. Heavy oil has less separation efficiency compared to light oil due to density difference and more wax content present in heavy oil which reduces the effective pore size.

\section{(5) Temperature}

The change in temperature will change density of fluid. As per Qing et al. (2017), it will not be affecting the efficiency of PTFE membrane. But it will be affecting hydrocyclonebased DOWS system. Reason is difference in density of fluids will be lesser with decreasing temperature which slows down the separation process. Hydrocyclone required oil density higher than $985.052 \mathrm{~kg} / \mathrm{m}^{3}$ (120 API). Maximum operating temperature is around $130^{\circ} \mathrm{C}\left(266^{\circ} \mathrm{F}\right)$.

\section{Addressing constraints of membrane-based separation DOWS}

\section{(a) Possible high-pressure separation membrane support configurations}

There has been significant research carried out to develop a support system which can support separation at very high pressures ranging from 1500 to 10,000 psi (Rosenthal 1991). The membrane science has advance to enhance the supports of membrane in terms of cost and performance, enhancing flow dynamics to reduce fouling and chocking issues, obtaining greater separation flows and in-place membrane restoring capacity. The following systems which can enhance concerned need has been developed and studied so far.
1. Tubular reinforcement ranging from 0.5 to 1 inches in OD consists of plastic sheets embraced of very fine pores which can enhance the capacity of separation to $600 \mathrm{psi}$. If this module is properly supported, for example, with stainless steel wire brad, then it can function at 1500 psi (Li 1972; Smith et al. 1970). Thus, modifying supports can develop a large range of operating pressure based on thickness of sheet and degree of reinforcement. The membrane can be inserted in the support by backing it with material to provide sufficient toughness for installation and uninstalling it.

2. McDonnell Douglas Co. conducted a study on shell and tube design. The studied shell and tube design consist of bundle of porous or perforated support tubes within a high-pressure shell ( $\mathrm{Li}$ 1972). The recent design employs 0.25 -inches-diameter porous ceramic tubes coated in situ with cellulose acetate (Smith et al. 1970; Littamann et al. 1971). The possible advantage of this design includes (a) decreasing fouling issues, (b) easy installation and uninstallation of membrane, (c) in-place membrane replacement capacity, (d) allowing greater operation pressures. Apart from academic researches, many companies like SPI supplies have developed the support technology which can separate liquids at 2000psi (SPM Filters 2000).

\section{(b) Fouling issues in PTFE membrane-based DOWS}

Generally, there are two types of fouling: (1) irreversible and (2) reversible. The fouling due to the fines migration is considered to be reversible fouling. Still fines plugging can be considered to be crucial for blocking the membranes temporarily. As a remedy, the length of module can be increased by adding up the stacks. The fines will plug the lower modules first, and gradually the plugging will move toward the upside. After a certain time, applying back pressure to the module will release the reversible fine plugging. Other remedies include: The module setup can be de-latched with certain over pull for cleaning purposes. As they are suspended in the tension, there is less chance of fouling and clogging. However, if so then they tend to be de-latched and gas circulation can be established for cleaning. There can be two mechanisms for cleaning. (1) Conventional gas circulation from string and rotation from the surface can be given for cleaning. (2) Reverse circulation of gas, which is entering from the annulus and from the water chamber to get inside of membrane with cleaning whole membrane (Fig. 5). It can be easily got onto the surface and replaced in case of more damage to its pores and filtration capability. Fouling can be controlled with physical, chemical and biological methods (Al Ashhab et al. 2017; Warsinger et al. 2016). Backwashing and alternating tangential flow applying with pump can be utilized for physical cleaning of fouling (Goosen et al. 2005). Another 


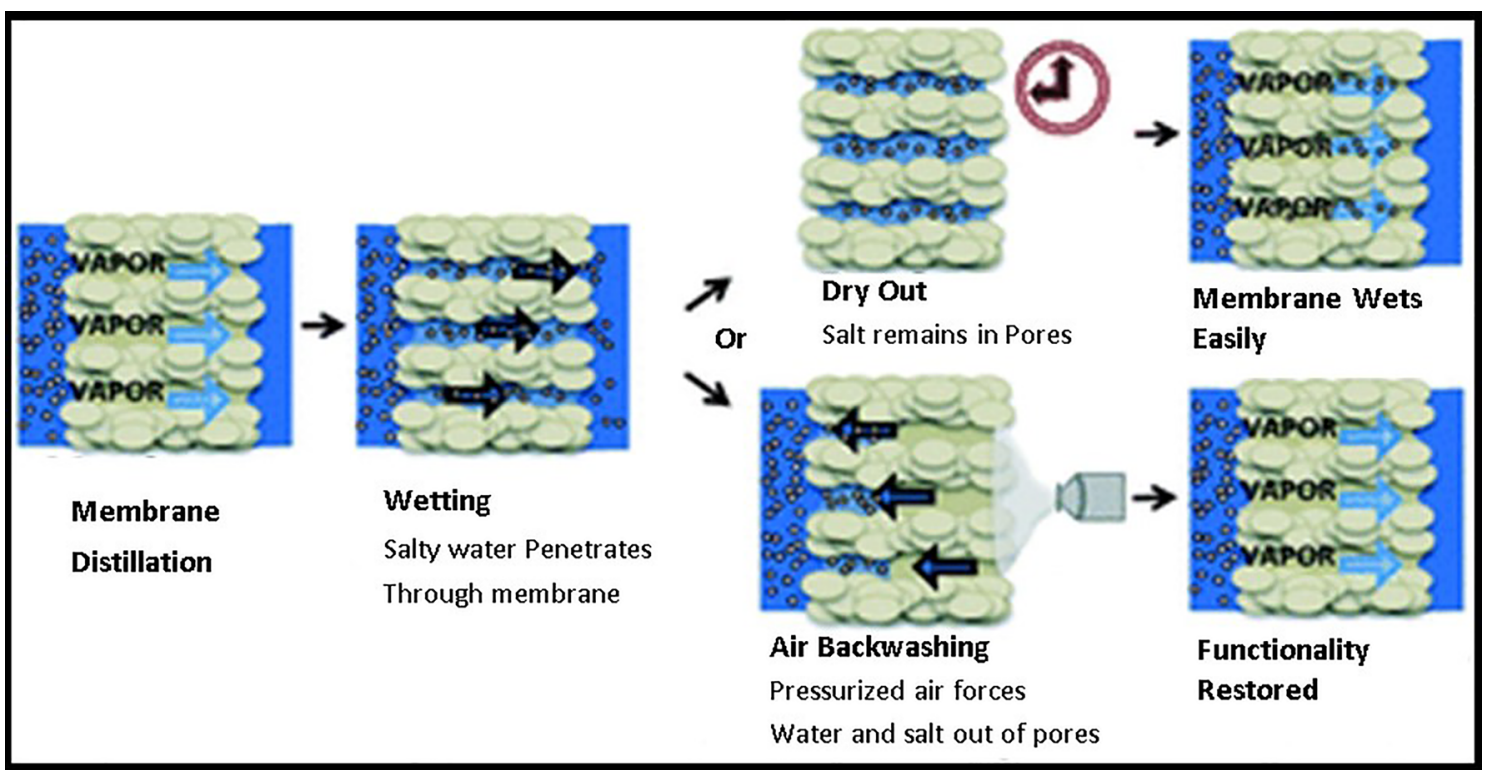

Fig. 5 Physical fouling control

physical cleaning, 24-h dryout of membrane or pressurized air application or both will revert the wettability of membrane and back to the normal operation (Warsinger et al. 2017). Fouling by mineral precipitation can be easily dissolved in sodium hydroxide, sodium hypochlorite and citric acid with respect to mineral without damaging the membrane (Hong and Elimelech 1997).

\section{Conclusion}

The downhole water separation technique installed in high water cut fields has demonstrated an increment in total oil volume produced with reducing lifting and handling costs to significant amount along with providing aesthetic value to environment. The conventional hydrocyclone-based DOWS and gravity separation-based DOWS have their inherent constraints in terms of separation efficiency, cost complexity, failure and controlling. The proposed membrane-based separation addresses all these issues due to its mechanical simplicity and flexibility in selecting disposal zone and geometry. Moreover, the proposed PTFE membrane has better oil separation efficiency as in separates at nanolevel and less pressure drop compared to the conventional DOWS techniques. PTFE membrane has good corrosion resistivity property in both acidic and alkaline environments. The membrane has great mechanical strength, and it doesn't dissolve easily in any solvent. The membrane can allow the flow of $1215 \mathrm{~L} \mathrm{~m}^{-2} \mathrm{~h}^{-1}$ at gravity separation, and its efficiency does not decrease with the change in temperature. Furthermore, the major constraints associated with the practicality of membrane like durable range of separation pressure, fouling, separation process design and membraneshear durability can be addressed now with recent advancements in membrane science as elaborated above. If a well is not being able to produced according to the predefined drawdown due to the operating capacity of surface water handling facilities, then downhole water separation system can be very potential player to produce fluid according to the required drawdown. Thus, apart from separation it also helps in production enhancement which in turn improves the economic life of project.

Acknowledgements The authors are grateful to School of Petroleum Technology and Centre of Excellence for Geothermal Energy, Pandit Deendayal Petroleum University, for the permission to publish this research.

Authors' contribution All the authors make a substantial contribution to this manuscript. MP, JP, YP, NP and MS participated in drafting the manuscript. MP, JP, YP and NP wrote the main manuscript. All the authors discussed the results and implication on the manuscript at all stages.

Funding Not applicable.

Availability of data and material All relevant data and materials are presented in the main paper.

\section{Compliance with ethical standards}

Conflict of interest The authors declare that they have no conflict of interest. 
Open Access This article is licensed under a Creative Commons Attribution 4.0 International License, which permits use, sharing, adaptation, distribution and reproduction in any medium or format, as long as you give appropriate credit to the original author(s) and the source, provide a link to the Creative Commons licence, and indicate if changes were made. The images or other third party material in this article are included in the article's Creative Commons licence, unless indicated otherwise in a credit line to the material. If material is not included in the article's Creative Commons licence and your intended use is not permitted by statutory regulation or exceeds the permitted use, you will need to obtain permission directly from the copyright holder. To view a copy of this licence, visit http://creativecommons.org/licenses/by/4.0/.

\section{References}

Awab O, Mohammed M (2015) Downhole separation technology. University of Khartoum

Al Ashhab A, Sweity A, Bayramoglu B, Herzberg M, Gillor O (2017) Biofouling of reverse osmosis membranes: effects of cleaning on biofilm microbial communities, membrane performance, and adherence of extracellular polymeric substances. Biofouling 33(5):397-409

Alhoni MA, Jerbi KK, Drawil TA, Co WO, Zekri AY, Arab U (2003) Application of downhole oil-water separation: a feasibility study. In: SPE Asia Pacific oil and gas conference and exhibition, Society of petroleum engineers

Blanco AE, Davies DR (2001) Technical and economic application guidelines for downhole oil-water separation technology. In: Paper SPE 67182 presented at the 2001 SPE production and operations symposium, Oklahoma City, OK

Burkarter E, Saul CK, Thomazi F, Cruz NC, Roman LS, Schreiner WH (2007) Superhydrophobic electrosprayedPTFE. Surf Coat Technol 202:194-198

Celia E, Darmanin T, de Givenchy E, Amigoni S (2013) Recent advances in designing superhydrophobic surfaces. J Colloid Interface Sci 402:1-18

Crabtree M, Romano C (2000) Water control. Oilfield Rev 12(1):30-51

Darjani S, Koplik J, Pauchard V (2017) Extracting the equation of state of lattice gases from random sequential adsorption simulations by means of the Gibbs adsorption isotherm. Phys Rev E 96(5):052803

Fakhrul-Razi A, Pendashteh A, Abdullah LC, Biak DRA, Madaeni SS, Abidin ZZ (2009) Review of technologies for oil and gas produced water treatment. J Hazard Mater 170:530-551

Fernández LG, Soria CO, Tourn CAG, Izquierdo MS (2001) The study of oil/water separation in emulsion by membrane technology. In: Soc Pet Eng

Frick BD, Filtration Group (2017) Tubular membrane filter system in operation. membrane technology, pp 22-25. Retrieved from http:// www.filtnews.com/

Gao C, Rivero M, Nakagawa E, Sanchez G (2007) Downhole separation technology—past, present and future. APPEA J 47(1):283-292

Goosen MFA, Sablani SS, Al-Hinai H, Al-Obeidani S, Al-Belushi R, Jackson D (2005) Fouling of reverse osmosis and ultrafiltration membranes: a critical review. Sep Sci Technol 39(10):2261-2297

Hong S, Elimelech M (1997) Chemical and physical aspects of natural organic matter (NOM) fouling of nanofiltration membranes. J Membr Sci 132(2):159-181

Jokhio SA, Berry MR, Bangash YK (2002) DOWS (Downhole OilWater Separation) cross-waterflood economics. In: Paper SPE 75273 presented at the 2002 SPE/DOE improved oil recovery symposium, Tulsa, OK
Li NNP (1972) Recent developments in separation science. CRC Press, Boca Raton. https://doi.org/10.1201/9781351076227

Li W, Ivanov S, Mozaffari S, Shanaiah N, Karima AM (2018) Palladium acetate trimer: understanding its ligand induced dissociation thermochemistry using isothermal titration calorimetry $\mathrm{x}$-ray absorption fine structure, and 31P nuclear magnetic resonance. Organometallics 38(2):451-460

Liao Y, Wang R, Fane AG (2013) Engineering superhydrophobic surface on poly (vinylidene fluoride) nanofiber membranes for direct contact membrane distillation. J Membr Sci 440:77-87

Littamann FF, Bishop H, Mcmillen R (1971) OSW research and development progress report No. 701, September

Marriott JI (2001) Detailed modelling and optimal design of membrane separation systems, Ph.D. Thesis

Matthews CM, Chachula R, Peachey BR, Solanki SC (1992) Application of downhole oil/water separation systems in the alliance field. In: SPE health, safety and environment in oil and gas exploration and production conference. Society of petroleum engineers

Mozaffari S, Tchoukov P, Atias J, Czarnecki J, Nazemifard N (2015) Effect of asphaltenes aggregation on rheological properties of diluted athabasca. Energy Fuels 29(9):5595-5599

Mozaffari S, Tchoukov P, Mozaffari A, Atias J, Czarnecki J, Nazemifard N (2016) Capillary driven flow in nanochannels - application to heavy oilrheology studies. Colloids Surf A 513:178-187

Mozaffari S, Li W, Thompson C, Ivanov S, Seifert S, Lee B, Kovarik L, Karima AM (2017) Colloidal nanoparticle size control: Experimental and kinetic modeling investigation of the ligand-metal binding role in controlling the nucleation and growth kinetics. Nanoscale 9(36):13772-13785

Mozaffari S, Li W, Thompson C, Ivanov S, Seifert S, Lee B, Kovarik L, Karim AM (2018) Ligand-mediated nucleation and growth of palladium metal nanoparticles. J Vis Exp 136:e57667

Nuraje N, Khan WS, Lei Y, Ceylan M, Asmatulu R, Ma M et al (2013) Superhydrophobic electrospun nanofibers. J Mater Chem A 1:1929-1946

Ogunsina OO, Wiggins ML (2005) A review of downhole separation technology. In: SPE Prod Oper Symp, pp 1-8

Papakostas V (2017) Oil-in-water emulsions: techniques and processes for maximizing the oil recovery in high water cut oil wells. In: Tech Univ Crete Sch Miner Resour Pet Eng

Peats A, Schrenkel P (1997) Application of ESP oil water separation system in the Swan Hills unit one field-a case study. In: SPE 39079 presented at the SPE electric submersible pump workshop, 30 April, Houston, Texas

Qing W, Shi X, Deng Y, Zhang W, Wang J, Tang CY (2017) Robust superhydrophobic-superoleophilic polytetrafluoroethylene nanofibrous membrane for oil/water separation. J Membr Sci 540:354361. https://doi.org/10.1016/j.memsci.2017.06.060

Raza A, Ding B, Zainab G, El-Newehy M, Al-Deyab SS, Yu J et al (2014) In situ cross-linked superwetting nanofibrous membranes for ultrafast oil-water separation. J Mater Chem A 2:10137-10145

Rosenthal PE (1991) United States Patent (19) Laverty, Jr. 54

Samco Technologies (n.d.) The essential guide to microfiltration and ultrafiltration

Smith HP, Uniroyal INC, Saline water conversion report 1970-1971, p 336

SPC PromVodOchistka LTD (n.d.) Water treatment hydrocyclones. Retrieved from https://prom-water.ru/en/catalog/industrial_water _treatment_systems/water_treatment_hydrocyclones/

SPM Filters (2000) Technical 2-4

Tweheyo MT, Akervoll I, Holt T, Torsæter O (2003) Simulations of oil-wet membrane wells for water-free oil production and downhole separation. In: Proc SPE Lat Am Caribb Pet Eng Conf, pp $1121-1131$

Veil JA (2001) Interest revives in downhole oil-water separators. Oil Gas J 99:47 
Vizzi M (2016) Membrane separations in biorefinery - Development of a general predictive model. Politecnico di Milano Scuola

Warsinger DM, Servi A, Van Belleghem S, Gonzalez J, Swaminathan J, Kharraz J et al (2016) Combining air recharging and membrane superhydrophobicity for fouling prevention in membrane distillation. J Membr Sci 505(January):241-252

Warsinger DM, Servi A, Connors GB, Mavukkandy MO, Arafat HA, Gleason KK, Lienhard VJH (2017) Reversing membrane wetting in membrane distillation: comparing dryout to backwashing with pressurized air. Environ Sci Water Res Technol 3(5):930-939. https://doi.org/10.1039/C7EW00085E

Xiong J, Huo P, Ko FK, Khanam N, Mikoryak C, Draper RK et al (2009) Fabrication of ultrafine fibrous polytetrafluoroethylene porous membranes by electrospinning. J Mater Res 24:2755-2761

Yang X, Wang R, Fane AG, Tang CY, Wenten IG (2013) Membrane module design and dynamic shear-induced techniques to enhance liquid separation by hollow fiber modules: a review. Desalin Water Treat 51:3604-3627

Yong J, Fang Y, Chen F, Huo J, Yang Q, Bian H (2016) Femtosecond laser ablated durable superhydrophobic PTFE films with microthrough-holes for oil/water separation: Separating oil from water and corrosive solutions. Appl Surf Sci 389:1148-1155

Zhou T, Yao Y, Xiang R, Wu Y (2014) Formation and characterization of polytetrafluoroethylene nanofiber membranes for vacuum membrane distillation. J Membr Sci 453:402-408

Publisher's Note Springer Nature remains neutral with regard to jurisdictional claims in published maps and institutional affiliations. 